\title{
Acoustic Velocity Log Numerical Simulation and Saturation Estimation of Gas Hydrate Reservoir in Shenhu Area, South China Sea
}

\author{
Kun Xiao, ${ }^{1,2}$ Changchun Zou, ${ }^{1,2}$ Biao Xiang, ${ }^{1,2}$ and Jieqiong Liu ${ }^{1,2}$ \\ ${ }^{1}$ School of Geophysics and Information Technology, China University of Geosciences, Beijing 10083, China \\ ${ }^{2}$ Key Laboratory of Geo-detection (China University of Geosciences, Beijing), Ministry of Education, Beijing 100083, China \\ Correspondence should be addressed to Changchun Zou; zoucc@cugb.edu.cn
}

Received 19 March 2013; Accepted 21 May 2013

Academic Editors: A. Billi and U. Tinivella

Copyright (c) 2013 Kun Xiao et al. This is an open access article distributed under the Creative Commons Attribution License, which permits unrestricted use, distribution, and reproduction in any medium, provided the original work is properly cited.

\begin{abstract}
Gas hydrate model and free gas model are established, and two-phase theory (TPT) for numerical simulation of elastic wave velocity is adopted to investigate the unconsolidated deep-water sedimentary strata in Shenhu area, South China Sea. The relationships between compression wave (P wave) velocity and gas hydrate saturation, free gas saturation, and sediment porosity at site $\mathrm{SH} 2$ are studied, respectively, and gas hydrate saturation of research area is estimated by gas hydrate model. In depth of 50 to $245 \mathrm{~m}$ below seafloor (mbsf), as sediment porosity decreases, $\mathrm{P}$ wave velocity increases gradually; as gas hydrate saturation increases, $\mathrm{P}$ wave velocity increases gradually; as free gas saturation increases, $\mathrm{P}$ wave velocity decreases. This rule is almost consistent with the previous research result. In depth of 195 to $220 \mathrm{mbsf}$, the actual measurement of $\mathrm{P}$ wave velocity increases significantly relative to the $\mathrm{P}$ wave velocity of saturated water modeling, and this layer is determined to be rich in gas hydrate. The average value of gas hydrate saturation estimated from the TPT model is $23.2 \%$, and the maximum saturation is $31.5 \%$, which is basically in accordance with simplified three-phase equation (STPE), effective medium theory (EMT), resistivity log (Rt), and chloride anomaly method.
\end{abstract}

\section{Introduction}

Gas hydrate mainly exists in the seafloor and polar permafrost [1], and it owns the cage structure of solid crystal, which is formed by water molecules and natural gas (usually dominated by methane). The formation of gas hydrate needs a low-temperature and high-pressure environment, and the concentration of methane must exceed its solubility in the pore water. So gas hydrate is commonly distributed in the water depth greater than $300 \mathrm{~m}$ in the continental slope belt $[2,3]$. The submarine gas hydrate reserves mainly depend on the distribution of gas hydrate area, the thickness of gas hydrate stability zone, the porosity of sedimentary layer, the saturation of gas hydrate, and so on. However, the accurate estimation of gas hydrate reserves is very difficult due to the lack of research on the determination of gas hydrate distribution and gas hydrate saturation. As gas hydrate is rich in methane, it is associated with a series of scientific issues [4], including the global carbon cycle [5], global temperature changes [6], the sea-level rise [7], and future energy supply [8]. Therefore, researches on determining gas hydrate distribution and estimating gas hydrate saturation have become the focus of the scientists all over the world. In May 2007, the gas hydrate samples and various log data of gas hydrate zone were firstly obtained in Shenhu area, South China Sea, which made a significant breakthrough in exploration of gas hydrate in China. Meanwhile, it provided a great convenience for investigating the properties of the gas hydrate reservoir [9].

Geophysical logging is an important tool for evaluating gas hydrate saturation, and valuable information can be obtained by studying the resistivity and acoustic velocity log data. According to the log data in Shenhu area, South China Sea, Chinese scholars have utilized some theoretical models and empirical formulas to estimate gas hydrate saturation [10-14], and the results of these researches have greatly promoted the process of studying gas hydrate saturation by using log data in China. However, previous studies mainly 
focused on the estimation of the gas hydrate saturation, and the discrepancy of the estimation of gas hydrate saturation was large because of the application of various methods. Besides, previous studies did not systematically study the relationship between any two of the gas hydrate saturation, elastic wave velocity, and sediment porosity, which led to incomplete understanding of the log data.

Foreign scholars have carried out researches on the evaluation of the marine gas hydrate saturation earlier. A variety of theoretical models or experimental models have been proposed to estimate gas hydrate saturation, such as Wyllie et al. [15] time average equation with the seismic velocity [16-18], the effective medium theory [19-23], Biot-Gassmann theory model [24-27], compression wave ( $\mathrm{P}$ wave) velocity of thermal-elastic theory [28], the three-phase equation (TPE) [29-34], and velocity model theory based on the two-phase theory (TPT) model [35]. Moreover, Tinivella et al. [36] made a research to compare the TPT model with the TPE model for evaluating gas hydrate saturations in marine sediments, and the comparison showed that the two theoretical approaches were in very good agreement. Based on this, the TPT model has been applied to verify the TPE model and estimate the gas hydrate and free gas saturations in several different areas [37-39].

In this work, based on the log data at site $\mathrm{SH} 2$ in Shenhu Area, we first establish gas hydrate model and free gas model by applying elastic wave velocity numerical model of the TPT method, then study the dependence of the $\mathrm{P}$ wave velocity on gas hydrate saturation, free gas saturation, and sediment porosity, and finally choose the gas hydrate model to estimate gas hydrate saturation at site $\mathrm{SH} 2$.

\section{Numerical Simulation of Elastic Wave Velocity by the TPT Model}

The TPT model $[41,42]$, which supposes that the rock solid part is composed of rock matrix and gas hydrate and that the rock pore fluid is composed of free gas and water, can be used to study the elastic wave velocity model about the elastic characteristics of marine sand-shale reservoirs. Based on this theory and using the reported in Tinivella [35], the velocity relation between $\mathrm{P}$ wave velocity $\left(V_{\mathrm{p}}\right)$ and shear wave ( $\mathrm{S}$ wave) velocity $\left(V_{s}\right)$ is as follows:

$$
\begin{aligned}
& V_{\mathrm{p}}=\{[ {\left[\frac{1}{C_{\mathrm{m}}}+\frac{4}{3} \mu\right) } \\
&\left.+\frac{\left(\phi_{\mathrm{eff}} / k\right)\left(\rho_{\mathrm{m}} / \rho_{\mathrm{f}}\right)+\left(1-\beta-2\left(\phi_{\mathrm{eff}} / k\right)\right)(1-\beta)}{\left(1-\phi_{\mathrm{eff}}-\beta\right) C_{\mathrm{b}}+\phi_{\mathrm{eff}} C_{\mathrm{f}}}\right] \\
&\left.\cdot \frac{1}{\rho_{\mathrm{m}}\left(1-\left(\phi_{\mathrm{eff}} / k\right)\left(\rho_{\mathrm{f}} / \rho_{\mathrm{m}}\right)\right)}\right\}^{1 / 2}, \\
& V_{\mathrm{s}}=\left\{\frac{\mu}{\left\{\rho_{\mathrm{m}}\left[1-\left(\phi_{\mathrm{eff}} \cdot \rho_{\mathrm{f}}\right) /\left(k \cdot \rho_{\mathrm{m}}\right)\right]\right\}}\right\}^{1 / 2} .
\end{aligned}
$$

Where $\phi_{\text {eff }}$ is the effective porosity, $\mu$ is the average rigidity of the skeleton, $\rho_{\mathrm{m}}$ is the average density, $\rho_{\mathrm{f}}$ is the density of the fluid phase, $\beta$ is the proportionality coefficient, $k$ is the coupling factor, and $C_{\mathrm{b}}, C_{\mathrm{f}}$ and $C_{\mathrm{m}}$ are the compressibility of the solid phase, the fluid phase, and the matrix, respectively.

\section{Geological Setting}

Shenhu area is considered as one of the occurrences of gas hydrate, which is located in the middle of the northern slope of the South China Sea, between the Xisha Trough and the Dongsha Islands and Baiyun Sag of Zhu II depression of the Pearl River Mouth Basin (Figure 1). Shenhu area experienced a geological evolution process similar to the northern margin of the South China Sea and eventually formed the regional sedimentary sequences in which marine sediments were the dominant composition [43]. Taking the Cenozoic sedimentary strata in the Shenhu area, for example, it is about $1000-7000 \mathrm{~m}$, and the organic matter content is $0.46 \%-1.9 \%$ [44-46], which can provide the material base for gas hydrate. In recent years, some studies have confirmed that mud volcanoes, seafloor slips, mud diapers and other special structural units beneficial to the formation of gas hydrate are widely being developed in Shenhu area [47], and the bottom simulating reflections (BSRs) have also been identified using various geophysical methods in the northern South China Sea by Guangzhou Marine Geological Survey, China Geological Survey [48].

During April-June 2007, eight sites were drilled in Shenhu area (see Figure 2), among which, sites of SH2, SH3, and SH7 in water depth of 1105 to $1423 \mathrm{~m}$ were determined to contain gas hydrate in recovered core samples. The thickness of gas hydrate stability zone was about 10 to $25 \mathrm{~m}[9,49]$, and the sediment lithology in and above the zone was silt and silty clay respectively, according to the core data.

\section{Data Set Used in the Study}

As previous researchers have done much work on site $\mathrm{SH} 2$ $[10-14,40,50]$, many valuable references can be used to obtain better results and verify the reliability of our research, so we select site $\mathrm{SH} 2$ as the research object. The water depth of site $\mathrm{SH} 2$ is $1232 \mathrm{~m}$, and the maximum drilling depth is 245 mbsf. Figure 2 shows the conventional logs of site $\mathrm{SH} 2$. The measurement depth range is from 50 to $245 \mathrm{mbsf}$, and the measurement projects include caliper, density, natural gamma ray, acoustic, and resistivity logging. The occurrence of gas hydrate reservoir in this site appears to be "response characteristics of two high and two low" in the log curve, namely high resistivity, high natural gamma ray and low density, low acoustic time, especially for resistivity and acoustic logs. Besides, when the layer of well diameter changes, caliper curve can be used as the effective parameter to identify gas hydrate reservoir because the abnormality of other logs has nothing to do with the well condition.

Based on the previous research methods for the thickness of gas hydrate stability zone [51-53] and combined with the 


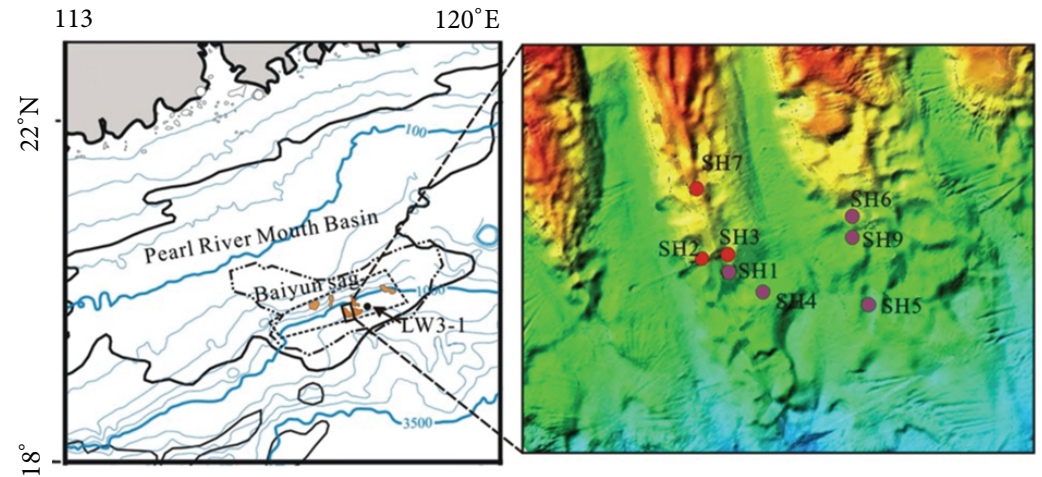

FIgURE 1: Areas of gas hydrate exploration and drilling area with drilling sites in the northern part of the South China Sea [40]. (Red dots, gas hydrate samples obtained; dark purple dots, no gas hydrate samples obtained.)

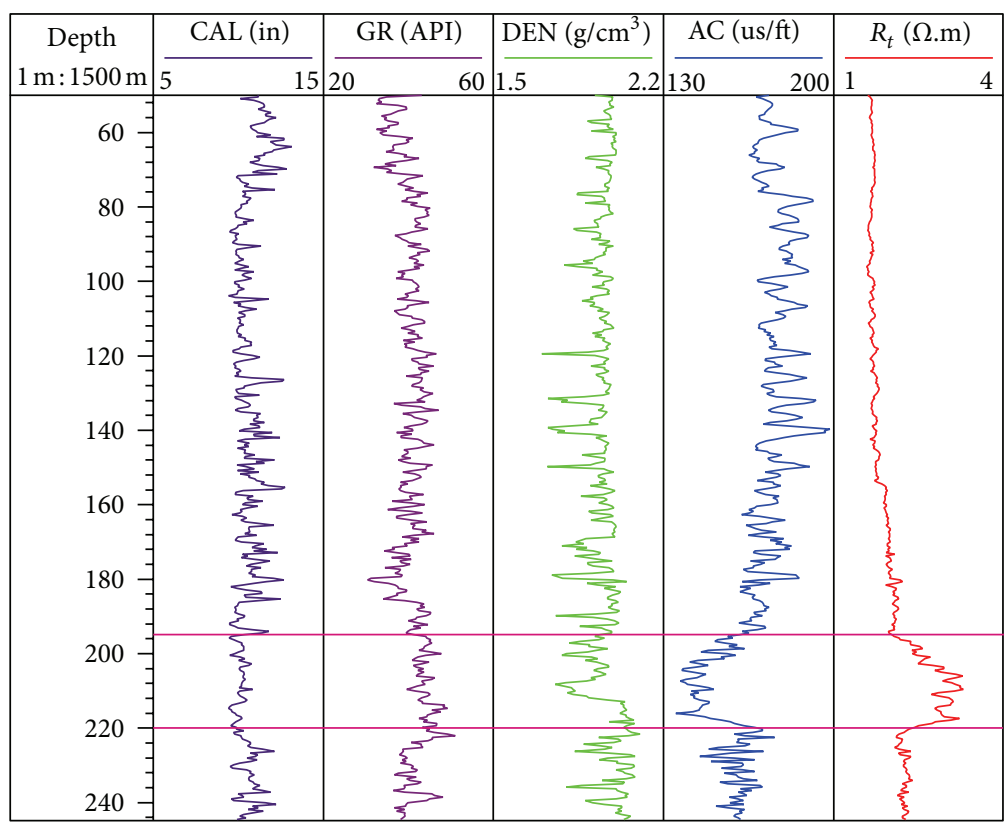

FIGURE 2: The conventional logs in site SH2 [10]. (The area delineated by a pink line is the occurrence of gas hydrate reservoir, and the depth range is 195 to 220 mbsf.)

analysis of conventional log data, the gas hydrate stability zone of site SH2 is determined to be at the depth of 195 to 220 mbsf [40].

\section{Methodology}

Seafloor sediments containing gas hydrate are generally composed of rock grain, gas hydrate, water, and natural gas. In order to research the characteristics of gas hydrate reservoir, gas hydrate model and free gas model have been established in this section, and based on these two models, the numerical simulation method and the TPT are used to study the dependence of the elastic wave velocity on sediment porosity, gas hydrate saturation and free gas saturation.

\subsection{Gas Hydrate Model}

5.1.1. Establishment of Gas Hydrate Model. The gas hydrate model assumes that the sediments are composed of rock grain, gas hydrate and water, and gas hydrate, is in the pore space, which is regarded as a part of the rock matrix. Supposing that $\phi_{\mathrm{s}}, \phi_{\mathrm{h}}, \phi_{\mathrm{w}}$, and $\phi_{\mathrm{g}}$ represent the volume percentage of rock grain, gas hydrate, water, and free gas in the sediments respectively, the gas hydrate model can be expressed as

$$
\begin{gathered}
\phi_{\mathrm{s}}+\phi_{\mathrm{h}}+\phi_{\mathrm{w}}=1, \\
\phi=\phi_{\mathrm{h}}+\phi_{\mathrm{w}},
\end{gathered}
$$

where $\phi$ is sediment porosity. 
Gas hydrate saturation $\left(S_{\mathrm{h}}\right)$ and water saturation $\left(S_{\mathrm{w}}\right)$ can be written as

$$
\begin{aligned}
& S_{\mathrm{h}}=\frac{\phi_{\mathrm{h}}}{\phi}, \\
& S_{\mathrm{w}}=\frac{\phi_{\mathrm{w}}}{\phi} .
\end{aligned}
$$

The volume percentages of rock grain in solid phase $\left(S_{\mathrm{s}}^{\prime}\right)$ and gas hydrate in the solid phase $\left(S_{\mathrm{h}}^{\prime}\right)$ can be written, respectively, as

$$
\begin{aligned}
& S_{\mathrm{s}}^{\prime}=\frac{\phi_{\mathrm{s}}}{\left(\phi_{\mathrm{s}}+\phi_{\mathrm{h}}\right)}, \\
& S_{\mathrm{h}}^{\prime}=\frac{\phi_{\mathrm{h}}}{\left(\phi_{\mathrm{s}}+\phi_{\mathrm{h}}\right)} .
\end{aligned}
$$

5.1.2. The Parameter Determination for Numerical Simulation of Gas Hydrate Model Based on the TPT. In order to apply the TPT to gas hydrate model, some parameters in (1) should be known. The parameters can be determined by Tinivella and Schon's derivation formula $[35,54]$.

(1) Effective porosity $\left(\phi_{\text {eff }}\right)$ can be written as

$$
\phi_{\text {eff }}=\left(1-S_{h}\right) \phi .
$$

(2) Average density of sediments $\left(\rho_{\mathrm{m}}\right)$, density of the solid phase $\left(\rho_{\mathrm{b}}\right)$, and density of the fluid phase $\left(\rho_{\mathrm{f}}\right)$ can be written as

$$
\begin{gathered}
\rho_{\mathrm{m}}=\left(1-\phi_{\mathrm{eff}}\right) \rho_{\mathrm{b}}+\phi_{\mathrm{eff}} \rho_{\mathrm{f}}, \\
\rho_{\mathrm{b}}=S_{\mathrm{s}}^{\prime} \rho_{\mathrm{s}}+S_{\mathrm{h}}^{\prime} \rho_{\mathrm{h}}, \\
\rho_{\mathrm{f}}=\rho_{\mathrm{w}},
\end{gathered}
$$

where $\rho_{\mathrm{s}}$ is density of the rock grain, $\rho_{\mathrm{h}}$ is gas hydrate density and $\rho_{\mathrm{w}}$ is water density.

(3) Assume that the solid compressibility lies between the Voigt and Reuss averages [54]. $C_{\mathrm{b}}$ can be written as

$$
C_{\mathrm{b}}=\frac{1}{2}\left(S_{\mathrm{s}}^{\prime} C_{\mathrm{s}}+S_{\mathrm{h}}^{\prime} C_{\mathrm{h}}\right)+\frac{1}{2}\left(\frac{S_{\mathrm{s}}^{\prime}}{C_{\mathrm{s}}}+\frac{S_{\mathrm{h}}^{\prime}}{C_{\mathrm{h}}}\right)^{-1},
$$

where $C_{\mathrm{s}}$ is rock grain compressibility and $C_{\mathrm{h}}$ is gas hydrate compressibility.

(4) Compressibility of the fluid phase $\left(C_{f}\right)$ is

$$
C_{\mathrm{f}}=C_{\mathrm{w}}
$$

where $C_{\mathrm{w}}$ is water compressibility.

(5) Compressibility of the matrix $\left(C_{\mathrm{m}}\right)$ indicates the compressibility of sediments without water, and it can be calculated by the following equation:

$$
C_{\mathrm{m}}=\left(1-\phi_{\mathrm{eff}}\right) C_{\mathrm{b}}+\phi_{\mathrm{eff}} C_{\mathrm{p}} \text {, }
$$

where $C_{p}$ is pore compressibility. The algorithm [35] to calculate $C_{\mathrm{p}}$ is:

$$
C_{\mathrm{p}}=\frac{\left(1-\phi_{\mathrm{eff}} / \phi_{0}\right)}{P_{\mathrm{d}}},
$$

where $\phi_{0}$ is the sediment porosity at the sea bottom and $P_{\mathrm{d}}$ is differential pressure.

(6) Proportional coefficient $(\beta)$ is

$$
\beta=\frac{C_{\mathrm{b}}}{C_{\mathrm{m}}} \text {. }
$$

(7) Shear modulus $(\mu)$ indicates average rigidity of the skeleton, and it can be calculated by the following equation:

$$
\mu=\left(\phi_{\mathrm{s}}+\phi_{\mathrm{h}}\right)\left[\frac{\phi_{\mathrm{s}} S_{\mathrm{s}}^{\prime}}{\mu_{\mathrm{sm}}}+\frac{S_{\mathrm{h}}^{\prime}}{\mu_{\mathrm{h}}}\right]^{-1},
$$

where $\mu_{\mathrm{h}}$ is gas hydrate rigidity and $\mu_{\mathrm{sm}}$ is the shear modulus of solid matrix with gas hydrate [55], which can be calculated by the following equation:

$$
\mu_{\mathrm{sm}}=\left(\mu_{\mathrm{smKT}}-\mu_{\mathrm{sm} 0}\right)\left[\frac{\phi_{\mathrm{h}}}{\left(1-\phi_{\mathrm{s}}\right)}\right]^{3.8}+\mu_{\mathrm{sm} 0} \text {, }
$$

where $\mu_{\text {smKT }}$ is Kuster and Toksoz's shear modulus [56] and $\mu_{\mathrm{sm} 0}$ is the shear modulus of solid matrix without gas hydrate.

5.1.3. Implementation Steps of Numerical Simulation of Gas Hydrate Model Based on the TPT. Consider the following.

(1) Given the $\phi$, or calculate it by the empirical formula.

(2) Given the $S_{\mathrm{h}}$ and $S_{\mathrm{w}}$, calculate $\phi_{\mathrm{s}}, \phi_{\mathrm{h}}, \phi_{\mathrm{w}}, S_{\mathrm{s}}^{\prime}$, and $S_{\mathrm{h}}^{\prime}$ according to (2)-(6).

(3) According to (7), calculate $\phi_{\text {eff }}$.

(4) According to (8) and (10), calculate $\rho_{\mathrm{b}}, \rho_{\mathrm{f}}$, and $\rho_{\mathrm{m}}$.

(5) According to (11)-(14), calculate $C_{\mathrm{b}}, C_{\mathrm{f}}$, and $C_{\mathrm{m}}$.

(6) According to (15), calculate $\beta$.

(7) According to (16) and (17), calculate $\mu$.

(8) According to (1), calculate $V_{\mathrm{p}}$.

\subsection{Free Gas Model}

5.2.1. Establishment of Free Gas Model. Free gas model assumes that the sediments are composed of rock grain, water, and free gas, and it can be expressed as

$$
\begin{gathered}
\phi_{\mathrm{s}}+\phi_{\mathrm{w}}+\phi_{\mathrm{g}}=1, \\
\phi=\phi_{\mathrm{w}}+\phi_{\mathrm{g}} .
\end{gathered}
$$


Water saturation $\left(S_{\mathrm{w}}\right)$ and free gas saturation $\left(S_{\mathrm{g}}\right)$ can be expressed as

$$
\begin{gathered}
S_{\mathrm{w}}=\frac{\phi_{\mathrm{w}}}{\phi}, \\
S_{\mathrm{g}}=\frac{\phi_{\mathrm{g}}}{\phi} .
\end{gathered}
$$

5.2.2. The Parameter Determination for Numerical Simulation of Free Gas Model Based on the TPT. Consider the following.

(1) $\phi_{\text {eff }}$ can be written as

$$
\phi_{\text {eff }}=\phi .
$$

(2) $\rho_{\mathrm{m}}, \rho_{\mathrm{b}}$, and $\rho_{\mathrm{f}}$ can be written as

$$
\begin{gathered}
\rho_{\mathrm{m}}=\left(1-\phi_{\mathrm{eff}}\right) \rho_{\mathrm{b}}+\phi_{\mathrm{eff}} \rho_{\mathrm{f}}=(1-\phi) \rho_{\mathrm{b}}+\phi \rho_{\mathrm{f}}, \\
\rho_{\mathrm{b}}=\rho_{\mathrm{s}}, \\
\rho_{\mathrm{f}}=S_{\mathrm{w}} \rho_{\mathrm{w}}+S_{\mathrm{g}} \rho_{\mathrm{g}},
\end{gathered}
$$

where $\rho_{\mathrm{g}}$ is free gas density.

(3) $C_{\mathrm{b}}$ can be written as

$$
C_{\mathrm{b}}=C_{\mathrm{s}}
$$

(4) Assume that the fluid compressibility lies between the Voigt and Reuss averages [54]. $C_{\mathrm{f}}$ can be written as

$$
C_{\mathrm{f}}=\frac{1}{2}\left(S_{\mathrm{w}} C_{\mathrm{w}}+S_{\mathrm{g}} C_{\mathrm{g}}\right)+\frac{1}{2}\left(\frac{S_{\mathrm{w}}}{C_{\mathrm{w}}}+\frac{S_{\mathrm{g}}}{C_{\mathrm{g}}}\right)^{-1},
$$

where $C_{\mathrm{g}}$ is the compressibility of free gas.

(5) $C_{m}$ is calculated by the same equation as that used in gas hydrate model.

(6) $\beta$ is calculated by the same equation as that used in gas hydrate model.

(7) $\mu$ can be written as

$$
\mu=\mu_{\mathrm{s}}, \quad \mu_{\mathrm{s}}=\frac{\mu_{\mathrm{sm} 0}}{1-\phi},
$$

where $\mu_{s}$ is rock grain rigidity.

(8) Variation range of $k$ is $1-\infty$.

5.2.3. Implementation Steps of Numerical Simulation of Free Gas Model Based on the TPT. Consider the following.

(1) Given the $\phi$, or calculate it by the empirical formula.

(2) Given the $S_{\mathrm{g}}$ and $S_{\mathrm{w}}$, calculate $\phi_{\mathrm{s}}, \phi_{\mathrm{w}}$, and $\phi_{\mathrm{g}}$ according to $(18)-(21)$.

(3) According to (22), calculate $\phi_{\text {eff }}$.

(4) According to (23) and (25), calculate $\rho_{\mathrm{b}}, \rho_{\mathrm{f}}$ and $\rho_{\mathrm{m}}$.

(5) According to (11)-(14), calculate $C_{\mathrm{b}}, C_{\mathrm{f}}$, and $C_{\mathrm{m}}$.

(6) According to (15), calculate $\beta$.

(7) According to (16) and (17), calculate $\mu$.

(8) According to (1), calculate $V_{\mathrm{p}}$.
5.3. Estimation of Sediment Porosity. Sediment porosity is a key parameter for the estimation of gas hydrate saturation for both gas hydrate and free gas models. Therefore, appropriate log data should be selected to estimate the sediment porosity at site $\mathrm{SH} 2$. The log data that can be applied to determine the sediment porosity include density, acoustic, resistivity, and neutron logging.

When it comes to the determination of sediment porosity by acoustic log, the data need to be corrected by the regional core data because seafloor sediments are always loose silt and silty clay. However, the core data is always insufficient, and it is difficult to determine the compaction correction coefficient, so acoustic log is not available. When it comes to the determination of sediment porosity by resistivity log, the Archie formula should be used to calculate porosity, and the Archie constants and formation water resistivity need to be known for the Archie formula [57]. However, the previous two parameters are generally determined by some empirical equations, and the estimation error of the sediment porosity is significant. As for the determination of sediment porosity by neutron log, it usually cannot be realized because of the lack of the neutron log data.

Compared with the resistivity, the acoustic and the density logs are less affected in gas hydrate reservoirs, and can generally reflect the situation of sediment porosity, so we select the density log data to estimate the sediment porosity in this study. The intensity of scattering gamma ray can be measured by the density log, which reflects electron density of the strata and volume density of rock $\left(\rho_{\mathrm{b}}\right)$. The estimation of $\phi$ by density log data can be expressed as [58]

$$
\phi=\frac{\left(\rho_{\mathrm{ma}}-\rho_{\mathrm{b}}\right)}{\left(\rho_{\mathrm{ma}}-\rho_{\mathrm{f}}\right)},
$$

where $\rho_{\mathrm{ma}}$ is matrix density and $\rho_{\mathrm{f}}$ is fluid density. Considering the effect of shaly sediments, (29) can be written as [58]

$$
\begin{gathered}
\phi=\frac{\left(\rho_{\mathrm{ma}}-\rho_{\mathrm{b}}\right)}{\left(\rho_{\mathrm{ma}}-\rho_{\mathrm{f}}\right)}-V_{\mathrm{sh}} \frac{\left(\rho_{\mathrm{ma}}-\rho_{\mathrm{sh}}\right)}{\left(\rho_{\mathrm{ma}}-\rho_{\mathrm{f}}\right)}, \\
V_{\mathrm{sh}}=\frac{\left(2^{\mathrm{GCUR} \times \mathrm{SH}}-1\right)}{\left(2^{\mathrm{GCUR}}-1\right)}, \\
\mathrm{SH}=\frac{\left(\mathrm{GR}-\mathrm{GR}_{\min }\right)}{\left(\mathrm{GR}_{\max }-\mathrm{GR}_{\min }\right)},
\end{gathered}
$$

where $V_{\mathrm{sh}}$ is the volume content of the shale, $\mathrm{SH}$ is the content index of the shale, $\rho_{\text {sh }}$ is the density of the shale, GR is the value of natural gamma log in the research interval, $\mathrm{GR}_{\min }$ is the value of natural gamma log in pure sandstone interval, $\mathrm{GR}_{\max }$ the is value of natural gamma log in pure mud interval, and GCUR is the Hilchie index, which is 3.7 in the Tertiary of North America and 2 in old stratum [59].

Equations (29) and (30) are used to calculate the sediment porosity at site $\mathrm{SH} 2$, and processing parameters can be set as follows: $\rho_{\mathrm{ma}}=2.65 \mathrm{~g} / \mathrm{cm}^{3}, \rho_{\mathrm{f}}=1.04 \mathrm{~g} / \mathrm{cm}^{3}, \rho_{\mathrm{sh}}=2.70 \mathrm{~g} / \mathrm{cm}^{3}$ $[12,35]$. The porosity calculated by $(29)$ and $(30)$ is close to each other (Figure 3), which varies in the range of $30 \%$ to $55 \%$, and the average value is $45 \%$. The result indicates that sediments at site $\mathrm{SH} 2$ are of high porosity. 


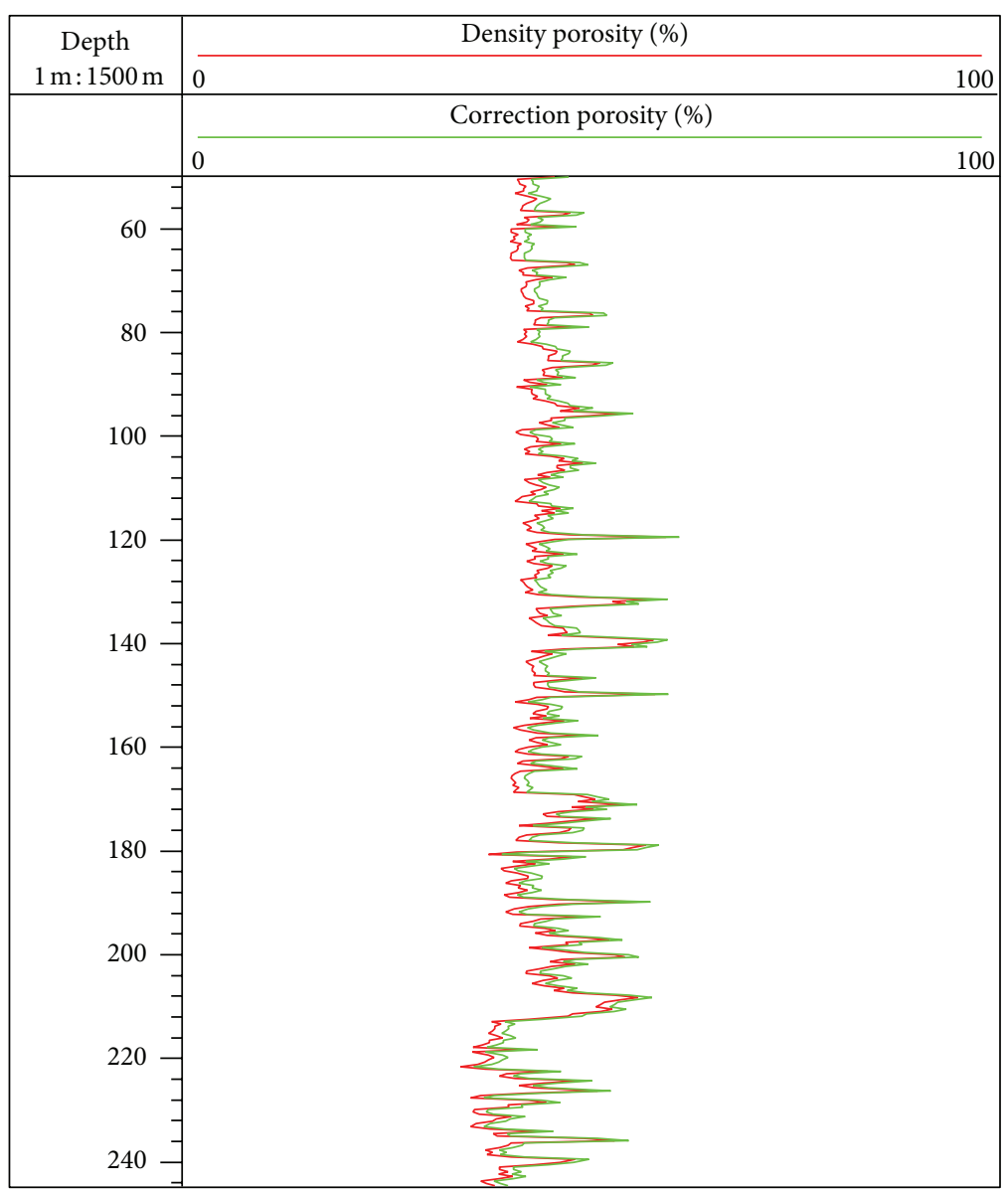

FIGURE 3: Result of sediment porosity calculated by density log data at site SH2. (Red line is the sediment porosity estimation used density log data; bright green line is the sediment porosity estimation which considered the effect of argillaceous sediments.)

\section{Results}

Gas hydrate model of the TPT is used to forward stimulate P wave velocity of sediment formation in different gas hydrate saturation conditions in depth of 50 to $245 \mathrm{mbsf}$ at site SH2. Table 1 shows the values of the main parameters used to evaluate the velocity. When $S_{h}=0$, we can get the $\mathrm{P}$ wave velocity of water saturated sediments forward stimulated by gas hydrate model based on the TPT. From Figure 4, the tendency between actual curve of $\mathrm{P}$ wave velocity $\log$ and $\mathrm{P}$ wave velocity curve of the saturated water condition is almost consistent in the gas hydrate interval (above $195 \mathrm{mbsf}$ ), so the model and its parameters are rational for numerical simulation in this study. The difference between actual $\mathrm{P}$ wave velocity of the $\log$ and $\mathrm{P}$ wave velocity of saturated water condition reflects the value of gas hydrate or free gas saturation, which can be used to qualitatively identify the gas hydrate reservoir. The specific response characteristics are as follows: the possibility of containing gas hydrate is dominant when the actual $\mathrm{P}$ wave velocity of the log is higher than $\mathrm{P}$ wave velocity of saturated water condition; the possibility of containing free gas is dominant when actual $\mathrm{P}$ wave velocity of the log is lower than the $\mathrm{P}$ wave velocity of saturated water condition [35]. In depth of 195 to 220 mbsf, actual P wave velocity of the log is significantly higher than the $\mathrm{P}$ wave velocity of saturated water condition, so this interval is the gas hydrate stability zone. In depth of 220 to $245 \mathrm{mbsf}$, the actual $\mathrm{P}$ wave velocity of the log has an increase relative to the $\mathrm{P}$ wave velocity of saturated water condition. However, Figure 2 does not indicate the increase of resistivity. Without the coring analysis data in this interval, whether the abnormality is caused by gas hydrate or not can not be ascertained, and should be researched in further study.

When $S_{h}$ gradually increases, $\mathrm{P}$ wave velocity made by forward stimulation also increases; when $S_{h}>15 \%, P$ wave velocity increases significantly; when $\mathrm{S}_{\mathrm{h}}=30 \%, \mathrm{P}$ wave velocity curve is located at the right of the actual $\mathrm{P}$ wave velocity logging curve. The above results indicate that the basic range of gas hydrate saturation is $0-30 \%$ in depth of 50 to $245 \mathrm{mbsf}$ at site $\mathrm{SH} 2$.

In order to study the dependence of $\mathrm{P}$ wave velocity on sediment porosity, gas hydrate saturation, it is assumed that values of gas hydrate saturation increase from 0 to 1 in the interval of 0.1 . Using gas hydrate model of the TPT to model the corresponding $\mathrm{P}$ wave velocity of the previous gas hydrate saturations, the relation surface of previous three properties can be formed as Figure 5 shows. With the increase of the sediment burial depth in depth of 50 to $245 \mathrm{mbsf}$ at site 


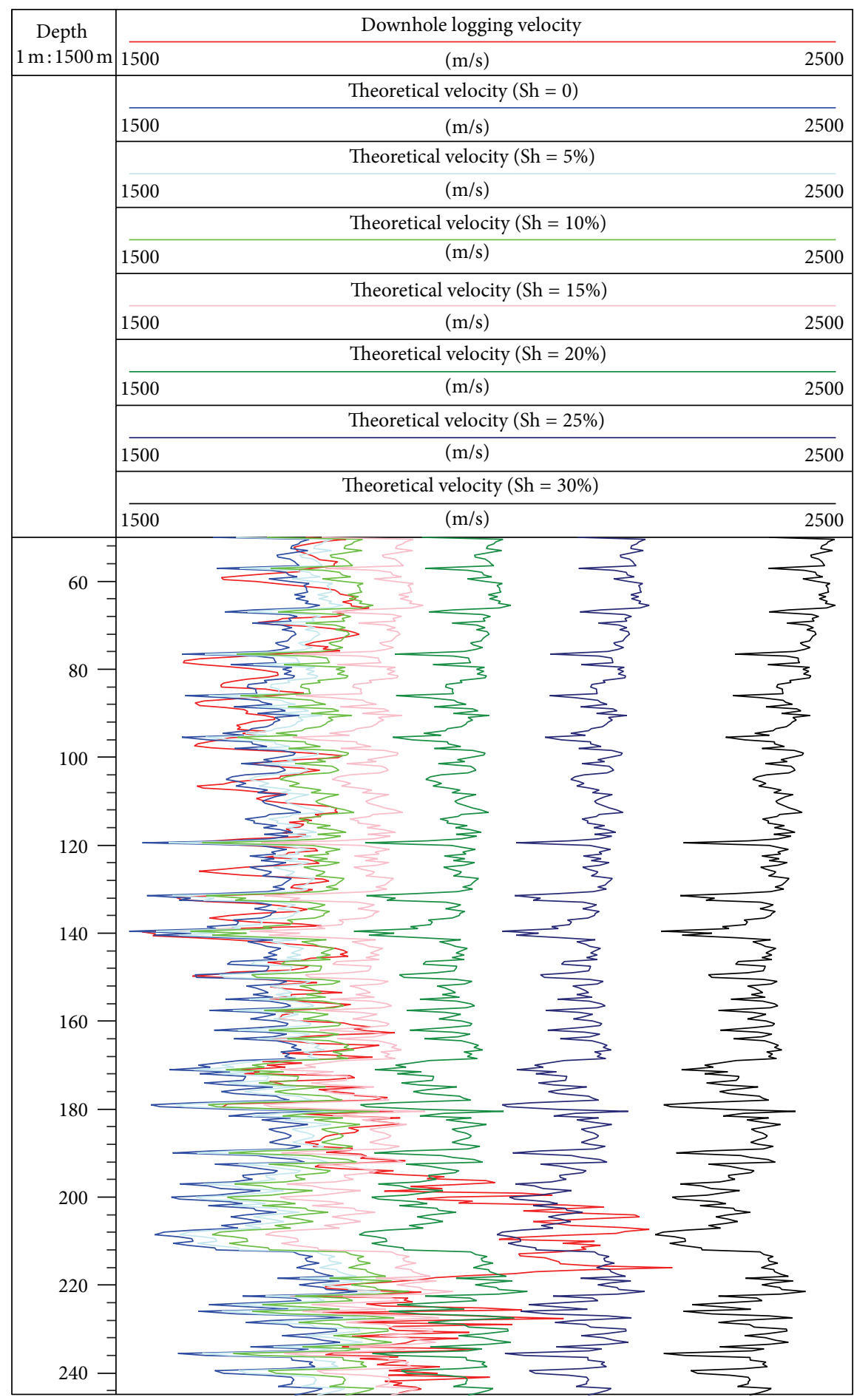

FIGURE 4: Forward stimulating P wave velocity of sediment formation at site SH2. (The red line is the actual log P wave velocity at site SH2; the blue line, sky blue line, bright green line, pink line, green line, dark blue line, and black line are assumed to $\mathrm{P}$ wave velocity made by forward modeling of the gas hydrate model when gas hydrate saturations are $0,5 \%, 10 \%, 15 \%, 20 \%, 25 \%$, and $30 \%$, resp.)

SH2, the porosity presents a decreasing trend except for the abnormality caused by borehole conditions in some intervals, and $\mathrm{P}$ wave velocity of forward stimulation $\left(\mathrm{S}_{\mathrm{h}}=0\right)$ slowly increases from 1743 to $1795 \mathrm{~m} / \mathrm{s}$. But with the increase of gas hydrate saturation, the increase rate of $\mathrm{P}$ wave velocity is obviously accelerated, and $\mathrm{P}$ wave velocity (burial depth is $51 \mathrm{mbsf}$ ) increases from 1743 to $3961 \mathrm{~m} / \mathrm{s}$. From the above analysis, the general rule between $\mathrm{P}$ wave velocity of forward stimulation and sediment porosity, gas hydrate saturation at site $\mathrm{SH} 2$ is the smaller the sediment porosity, the greater 
TABLE 1: Values of the main parameters of the gas hydrate and free gas model of the TPT.

\begin{tabular}{lcc}
\hline Parameters & Details & References \\
\hline$C_{\mathrm{s}}$ & $2.7 \times 10^{-11} \mathrm{~Pa}^{-1}$ & {$[60]$} \\
$C_{\mathrm{h}}$ & $1.79 \times 10^{-10} \mathrm{~Pa}^{-1}$ & {$[1]$} \\
$C_{\mathrm{w}}$ & $4.79 \times 10^{-10} \mathrm{~Pa}^{-1}$ & {$[61]$} \\
$C_{\mathrm{g}}$ & $4.24 \times 10^{-8} \mathrm{~Pa}^{-1}$ & {$[62]$} \\
$\rho_{\mathrm{s}}$ & $2650 \mathrm{~kg} / \mathrm{m}^{3}$ & {$[60]$} \\
$\rho_{\mathrm{w}}$ & $1040 \mathrm{~kg} / \mathrm{m}^{3}$ & {$[1]$} \\
$\rho_{\mathrm{g}}$ & $88.48 \mathrm{~kg} / \mathrm{m}^{3}$ & {$[62]$} \\
$\rho_{\mathrm{h}}$ & $767 \mathrm{~kg} / \mathrm{m}^{3}$ & {$[1]$} \\
& $116+4.65 z \mathrm{~m} / \mathrm{s}$ & {$[63]$} \\
$V_{\mathrm{s}}$ & $237+1.28 z \mathrm{~m} / \mathrm{s}$ & \\
& $332+0.58 z \mathrm{~m} / \mathrm{s}$ & {$[35]$} \\
$\mu_{\mathrm{sm} 0}$ & $\rho_{\mathrm{m}} V_{\mathrm{s}}^{2} \mathrm{~Pa}$ & {$[35]$} \\
$\mu_{\mathrm{h}}$ & $3.7 \times 10^{9} \mathrm{~Pa}$ & {$[61]$} \\
$k$ & 2.3 &
\end{tabular}

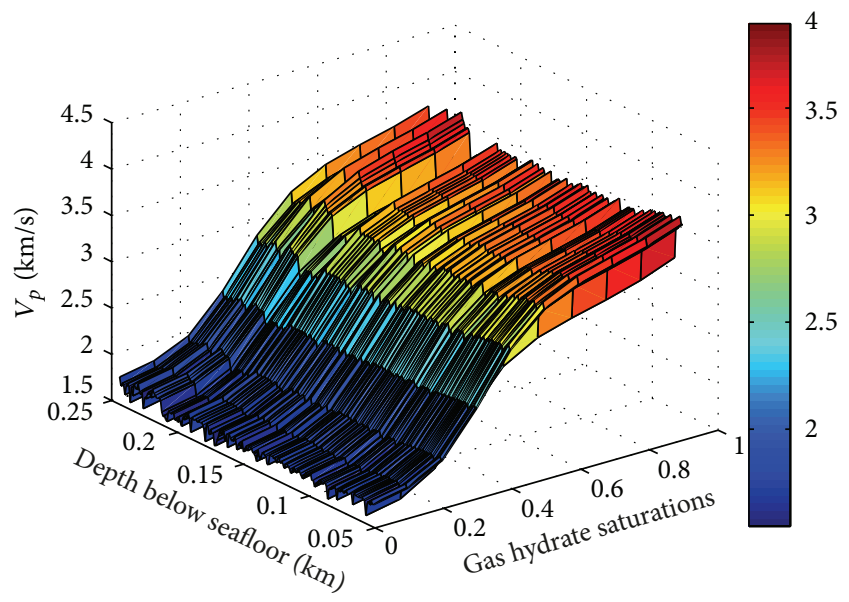

FIGURE 5: Relation between P wave velocity and sediment porosity, gas hydrate saturation at site $\mathrm{SH} 2$. (Because of the effect of variation of borehole conditions and actual sediments, the sediment porosity in some intervals does not reduce with the increasing depth and causes the curved surface unsmooth growth. In depth of 195 to 220 mbsf of gas hydrate reservoir, P wave velocity surface of forward simulation subsides as the sediment porosity relatively increases.)

the $\mathrm{P}$ wave velocity; the higher the gas hydrate saturation, the greater the $\mathrm{P}$ wave velocity. This result is basically in accordance with the research result made by Tinivella [35].

Similarly, it is assumed that values of free gas saturation increase from 0 to 1 in the interval of 0.1 in order to study the relation between $\mathrm{P}$ wave velocity and free gas saturation. Using free gas model of the TPT to model the corresponding $\mathrm{P}$ wave velocity of the previous free gas saturations, the relation surface of $\mathrm{P}$ wave velocity, sediment porosity, and free gas saturation can be formed as Figure 6 shows. In depth of 50 to $245 \mathrm{mbsf}$ at site $\mathrm{SH} 2$, with the increase of free gas saturation, $\mathrm{P}$ wave velocity (burial depth is $51 \mathrm{mbsf}$ ) decreases from 1773 to $597 \mathrm{~m} / \mathrm{s}$ (The velocity $597 \mathrm{~m} / \mathrm{s}$ is obtained

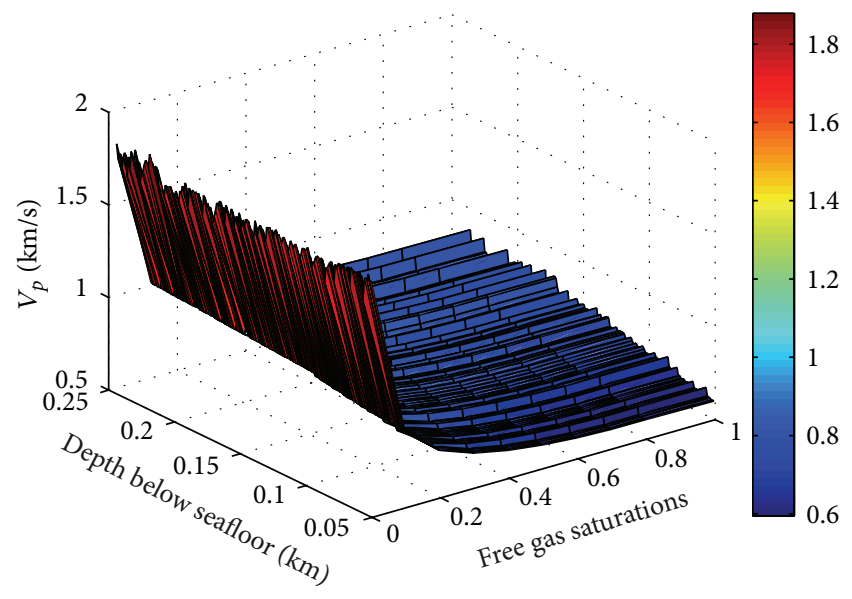

FIgURE 6: Relation between P wave velocity and sediment porosity, free gas saturation at site $\mathrm{SH} 2$. ( $\mathrm{P}$ wave velocity is easily affected by the free gas saturation. When the free gas saturation increases, $\mathrm{P}$ wave velocity of forward stimulation by the free gas model of the TPT decreases rapidly.)

supposing $100 \%$ free gas saturation), and the decrease rate is significant. Considering the depth effect, the decrease rate of $P$ wave velocity slows down with the increase of burial depth. From the above analysis, the general rule between $\mathrm{P}$ wave velocity of forward stimulation and free gas saturation at site $\mathrm{SH} 2$ is the higher the free gas saturation, the lower the $\mathrm{P}$ wave velocity. This result is also basically in accordance with the research result made by Tinivella [35].

The estimation of gas hydrate saturation for gas hydrate reservoir evaluation has an important significance. In order to estimate gas hydrate saturation in sediments, it is necessary to associate the $\mathrm{P}$ wave velocity of the $\log$ with the $\mathrm{P}$ wave velocity of gas hydrate model based on the TPT. Given an initial gas hydrate saturation, based on gas hydrate model of the TPT, the difference between $\mathrm{P}$ wave velocity of forward simulation and the actual $\mathrm{P}$ wave velocity of the $\log$ in this saturation can be acquired. If the difference is in the range of allowable error, the saturation can be treated as the actual saturation; if the difference does not satisfy the error requirement, the value of gas hydrate saturation should be modified until meeting the error precision.

Using gas hydrate model of the TPT to inverse gas hydrate saturation at site $\mathrm{SH} 2$, the values of the main parameters are listed in Table 1, and the inversion result is shown in Figure 7. In the interval of 50 to $90 \mathrm{mbsf}$ at site $\mathrm{SH} 2$, the range of gas hydrate saturation is $0-17.5 \%$, and the average value is $4.8 \%$. As the shallow sediments are influenced by variation of borehole conditions, the estimation error of gas hydrate saturation in this interval is significant, which should be noticed during the analysis. In the interval of 90 to $195 \mathrm{mbsf}$, the range of gas hydrate saturation is $0-18.9 \%$, and the average value is $7 \%$. In the interval of 195 to $220 \mathrm{mbsf}$, the range of gas hydrate saturation is $7-31.5 \%$, and the average value is $23.2 \%$. With the increase of burial depth, gas hydrate saturation gradually increases and finally reaches the peak value of $31.5 \%$ in 208 mbsf. Then the gas hydrate saturation decreases slowly 


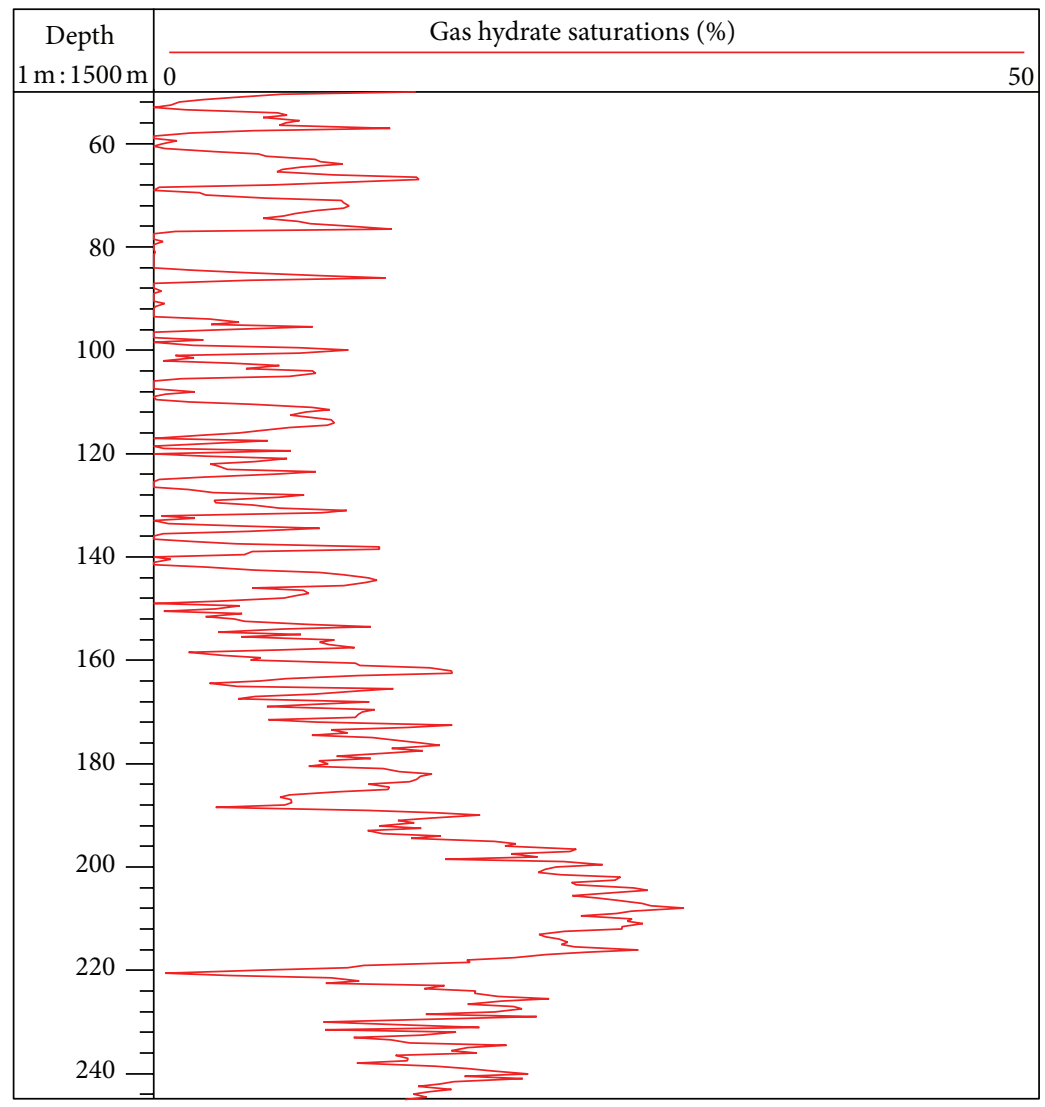

FIGURE 7: Estimation of gas hydrate saturation at site $\mathrm{SH}$.

with the increase of burial depth, and the range of gas hydrate saturation is $0-25.8 \%$ in the interval of 220 to $245 \mathrm{mbsf}$, with an average value of $15.5 \%$.

\section{Discussion}

It is very important to determine the porosity for the evaluation of gas hydrate saturation. In order to analyze the accuracy of porosity estimation by density log data, we use resistivity log data and combine the Archie formula [57] to make a comparison between the estimation results, and the comparison results are shown in Figure 8. The porosity estimated by resistivity log data generally changes in the range of 30 to $50 \%$, and the average value is $43 \%$ [12,64]. In the interval of 50 to $195 \mathrm{mbsf}$, the curves of density porosity and resistivity porosity are approximately coincident, while the former fluctuates due to the borehole effect. In the interval of 195 to $220 \mathrm{mbsf}$, the sediment contains gas hydrate, and the curve of resistivity porosity decreases significantly compared with the curve of density porosity due to the significant increase of resistivity (Figure 2), so the porosity calculated by resistivity log data needs to be corrected to exclude the influence of the increase of skeleton components. In the interval of 220 to $245 \mathrm{mbsf}$, the curves of density porosity and resistivity porosity are approximately coincident again. These results indicate that using density log data to estimate the porosity in the gas hydrate stability zone at site $\mathrm{SH} 2$ is relatively more reliable. According to previous studies, the range of core porosity by laboratory analysis in this interval was 40$55 \%$, which was almost coincident with the estimation of porosity by density log data in this study [13]. As Figure 8 shows, the core porosity distribution corresponds with the curve of density porosity of the well, and this result proves that the porosity estimated by density log data can meet the requirement for evaluating gas hydrate saturation at site $\mathrm{SH} 2$.

In order to verify the accuracy of gas hydrate saturation estimated by the TPT, we compare gas hydrate saturation in this study with that estimated by Wang et al. [50] in the occurrence of gas hydrate (195 to $220 \mathrm{mbsf}$ ) at site SH2 (Figure 9). The curve of gas hydrate saturation made by the TPT first increases and then decreases as the burial depth increases, which reaches the peak value of $31.5 \%$ in the 208 mbsfs and then decreases gradually. The peak value of gas hydrate saturation by the TPT is slightly smaller than the resistivity $\log (\mathrm{Rt})$ method $(40.5 \%)$, the simplified three-phase equation (STPE) method (41\%), and the effective medium theory (EMT) method (38.5\%). However, the curve trend of gas hydrate saturation estimated by the TPT and other three methods is basically consistent, and the difference only lies in the amplitude of the curve, which indicates that using the TPT method to estimate gas hydrate saturation at site $\mathrm{SH} 2$ is available. 


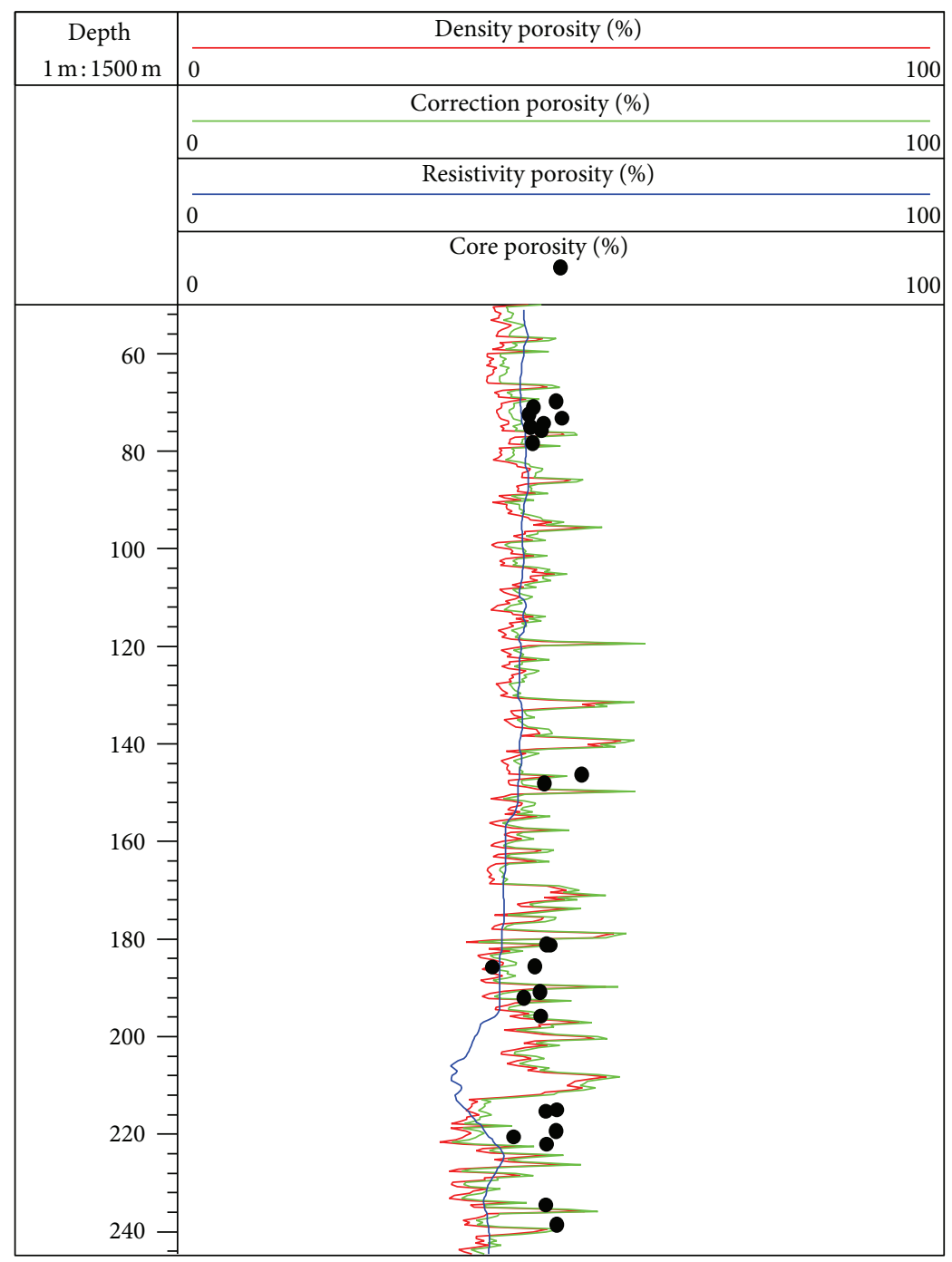

Figure 8: Comparison of estimation of sediment porosity made by different methods at site SH2. (The red curve is the porosity estimated by density log data; the bright green curve is the porosity considering the effect of shaly sediments; blue curve is the porosity estimated by resistivity log combined with Archie formula; the black dots are the porosity measured by core laboratory.)

The average value of gas hydrate saturations calculated by chloride anomaly method is $25 \%$, and the peak value is $45 \%$ [9]. The peak value of gas hydrate saturation estimated by the TPT is relatively lower than that estimated by chloride anomaly method, but the average values estimated by the two methods are basically same, and most distribution dots of gas hydrate saturations obtained by chloride anomaly method correspond with the curve of gas hydrate saturation estimated by the TPT method (Figure 9). This also indicates that using the TPT method to estimate gas hydrate saturation at site $\mathrm{SH} 2$ is available.

\section{Conclusions}

In summary, the relationships between $\mathrm{P}$ wave velocity and gas hydrate saturation, free gas saturation, and sediment porosity at site $\mathrm{SH} 2$ are studie, respectively, by virtue of elastic wave velocity of numerical stimulation based on the TPT, and gas hydrate model and free gas model are established to estimate the sediment porosity in order to determine the gas hydrate saturation of the research area. Some conclusions can be drawn as follows.

(1) Using the difference between $\mathrm{P}$ wave velocity of saturated water condition and actual $\mathrm{P}$ wave velocity of the log, whether the sediment contains gas hydrate or not can be identified quickly. In the interval of 195 to $220 \mathrm{mbsf}$ at site $\mathrm{SH} 2$, the actual $\mathrm{P}$ wave velocity of the $\log$ increases significantly relative to $\mathrm{P}$ wave velocity of forward stimulation in saturated water condition, so this interval is determined to contain gas hydrate.

(2) By virtue of elastic wave velocity of numerical stimulation based on the TPT, combined with log data, the dependence of $\mathrm{P}$ wave velocity on gas hydrate saturation, free gas saturation, and sediment porosity at site $\mathrm{SH} 2$ can be analyzed, respectively. In the interval of 50 to $245 \mathrm{mbsf}$, as sediment porosity decreases, $\mathrm{P}$ wave velocity gradually 


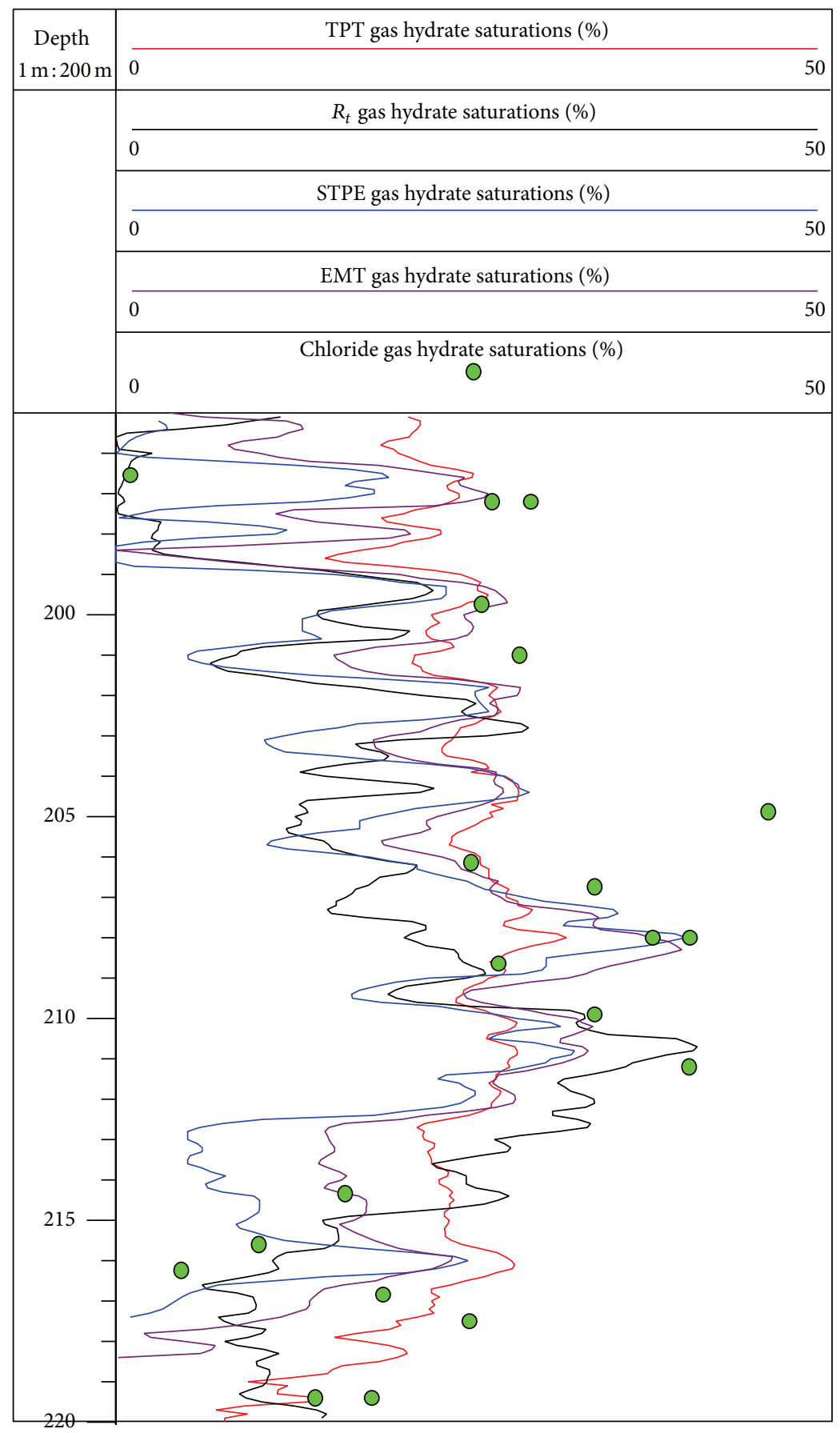

Figure 9: Comparison of estimation of gas hydrate saturation made by different methods in depth of 195 to 220 mbsf at site SH2. (The red curve, black curve, blue curve, and violet curve represent gas hydrate saturations estimated by the TPT, the Rt, the STPE, and the EMT method, respectively; the bright green dots represent gas hydrate saturations calculated by chloride anomaly method.)

increases; as gas hydrate saturation increases, $\mathrm{P}$ wave velocity increases; as free gas saturation increases, $\mathrm{P}$ wave velocity gradually decreases.

(3) The log data can be used to calculate gas hydrate saturation of the whole well, and the availability is better than the coring data. The average value of gas hydrate saturation estimated by the TPT is $23.2 \%$, and the peak value is $31.5 \%$, which is basically in accordance with the values estimated by the STPE model, the EMT model, the Rt model and chloride anomaly method.

\section{Acknowledgments}

This work was supported by the National Natural Science Foundation of China (no. 41274185) and the Fundamental Research Funds for the Central Universities (no. 2652011189, 
no. 2652012096). The authors wish to thank three reviewers (A. Billi, U. Tinivella, and the other anonymous reviewer) for their valuable and constructive comments and suggestions which helped them to improve their paper.

\section{References}

[1] E. D. Sloan, Clathrate Hydrate of Natural Gases, Marcel Dekker, New York, NY, USA, 2nd edition, 1990.

[2] G. R. Dickens, "The potential volume of oceanic methane hydrates with variable external conditions," Organic Geochemistry, vol. 32, no. 10, pp. 1179-1193, 2001.

[3] G. Bhatnagar, W. G. Chapman, G. R. Dickens, B. Dugan, and G. J. Hirasaki, "Generalization of gas hydrate distribution and saturation in marine sediments by scaling of thermodynamic and transport processes," American Journal of Science, vol. 307, no. 6, pp. 861-900, 2007.

[4] K. A. Kvenvolden, "Methane hydrate-a major reservoir of carbon in the shallow geosphere?" Chemical Geology, vol. 71, no. 1-3, pp. 41-51, 1988.

[5] G. R. Dickens, "Rethinking the global carbon cycle with a large, dynamic and microbially mediated gas hydrate capacitor," Earth and Planetary Science Letters, vol. 213, no. 3-4, pp. 169-183, 2003.

[6] D. Archer, "Methane hydrate stability and anthropogenic climate change," Biogeosciences, vol. 4, no. 4, pp. 521-544, 2007.

[7] M. Maslin, M. Owen, R. Betts, S. Day, T. D. Jones, and A. Ridgwell, "Gas hydrates: past and future geohazard?" Philosophical Transactions of the Royal Society A, vol. 368, no. 1919, pp. 23692393, 2010.

[8] T. S. Collett, "Energy resource potential of natural gas hydrates," AAPG Bulletin, vol. 86, no. 11, pp. 1971-1992, 2002.

[9] H. Q. Zhang, S. X. Yang, and N. Y. Wu, "GMGS-1 Science Team. Successful and surprising results for China's first gas hydrate drilling expedition. Fire in the Ice," Methane Hydrate Newsletter. National Energy Technology Laboratory, US Department of Energy, 2007.

[10] J. A. Lu, S. X. Yang, N. Y. Wu et al., "Well logging evaluation of gas hydrates in Shenhu area, South China Sea," Geoscience, vol. 22, no. 3, pp. 447-451, 2008 (Chinese).

[11] J. Liang, H. B. Wang, and Y. Q. Guo, "Study of seismic velocity about gas hydrates in the northern slope of the South China Sea," Geoscience, vol. 20, no. 1, pp. 123-129 (Chinese).

[12] X. J. Wang, S. G. Wu, X. W. Liu et al., "Estimation of gas hydrate saturation based on resistivity logging and analysis of estimation error," Geoscience, vol. 24, no. 5, pp. 993-999, 2010 (Chinese).

[13] Y. Q. Guo, S. H. Qiao, and W. J. LV, "Vertical distribution of gas hydrate in Shenhu area of the South China based on acoustic velocity," Marine Geology Frontiers, vol. 27, no. 7, pp. 7-12, 2011 (Chinese).

[14] H. Y. Gao, G. F. Zhong, J. Q. Liang et al., "Estimation of gas hydrate saturation with modified Biot-Gassmann theory: a case from Northern South China Sea," Marine Geology \& Quaternary Geology, vol. 32, no. 4, pp. 83-89, 2012 (Chinese).

[15] M. R. J. Wyllie, A. R. Gregory, and G. H. F. Gardner, "An experimental investigation of factors affecting elastic wave velocities in porous media," Geophysics, vol. 23, no. 3, pp. 459493, 1958.

[16] W. T. Wood, P. L. Stoffa, and T. H. Shipley, "Quantitative detection of methane hydrate through high-resolution seismic velocity analysis," Journal of Geophysical Research, vol. 99, no. 5, pp. 9681-9695, 1994.

[17] T. Yuan, R. D. Hyndman, G. D. Spence, and B. Desmons, "Seismic velocity increase and deep-sea gas hydrate concentration above a bottom-simulating reflector on the northern Cascadia continental slope," Journal of Geophysical Research B, vol. 101, no. 6, pp. 13655-13671, 1996.

[18] J. Korenaga, W. S. Holbrook, S. C. Singh, and T. A. Minshull, "Natural gas hydrates on the southeast U.S. margin: constraints from full waveform and travel time inversions of wide-angle seismic data," Journal of Geophysical Research B, vol. 102, no. 7, pp. 15345-15365, 1997.

[19] C. Ecker, J. Dvorkin, and A. Nur, "Sediments with gas hydrates: internal structure from seismic AVO," Geophysics, vol. 63, no. 5, pp. 1659-1669, 1998.

[20] M. B. Helgerud, J. Dvorkin, A. Nur, A. Sakai, and T. Collett, "Elastic-wave velocity in marine sediments with gas hydrates: effective medium modeling," Geophysical Research Letters, vol. 26, no. 13, pp. 2021-2024, 1999.

[21] M. Jakobsen, J. A. Hudson, T. A. Minshull, and S. C. Singh, "Elastic properties of hydrate-bearing sediments using effective medium theory," Journal of Geophysical Research B, vol. 105, no. 1, pp. 561-577, 2000.

[22] R. Ghosh, K. Sain, and M. Ojha, "Effective medium modeling of gas hydrate-filled fractures using the sonic log in the KrishnaGodavari basin, offshore eastern India," Journal of Geophysical Research B, vol. 115, no. 6, 2010.

[23] U. Shankar and M. Riedel, "Gas hydrate saturation in the Krishna-Godavari basin from P-wave velocity and electrical resistivity logs," Marine and Petroleum Geology, vol. 28, no. 10, pp. 1768-1778, 2011.

[24] C. Ecker, J. Dvorkin, and A. M. Nur, "Estimating the amount of gas hydrate and free gas from marine seismic data," Geophysics, vol. 65 , no. 2 , pp. $565-573,2000$.

[25] M. W. Lee and T. S. Collett, "Integrated analysis of well logs and seismic data to estimate gas hydrate concentrations at Keathley Canyon, Gulf of Mexico," Marine and Petroleum Geology, vol. 25, no. 9, pp. 924-931, 2008.

[26] M. W. Lee, "Biot-Gassmann theory for velocities of gas hydratebearing sediments," Geophysics, vol. 67, no. 6, pp. 1711-1719, 2002.

[27] M. W. Lee, "Well log analysis to assist the interpretation of 3D seismic data at Milne Point, North Slope of Alaska," U.S. Geological Survey, Scientific Investigation Report 2005-5048, 2005.

[28] X. Wang and X. Liu, "A method for estimating gas hydrate and free gas saturations in marine sediments," in Proceedings of the SPG/SEG 2004 International Geophysical Conference, pp. 852$855,2004$.

[29] M. W. Lee, D. R. Hutchinson, W. P. Dillon, J. J. Miller, W. F. Agena, and B. A. Swift, "Method of estimating the amount of in situ gas hydrates in deep marine sediments," Marine and Petroleum Geology, vol. 10, no. 5, pp. 493-506, 1993.

[30] M. W. Lee, D. R. Hutchinson, T. S. Collett, and W. P. Dillon, "Seismic velocities for hydrate-bearing sediments using weighted equation," Journal of Geophysical Research B, vol. 101, no. 9, pp. 20347-20358, 1996.

[31] M. W. Lee, "Velocities and attenuations of gas hydrate-bearing sediments," U.S. Geological Survey, Scientific Investigations Report 2007-5264, 2007. 
[32] M. W. Lee, "Models for gas hydrate-bearing sediments inferred from hydraulic permeability and elastic velocities," U.S. Geological Survey, Scientific Investigations Report 2008-5219, 2008.

[33] M. W. Lee and W. F. Waite, "Estimating pore-space gas hydrate saturations from well log acoustic data," Geochemistry, Geophysics, Geosystems, vol. 9, no. 7, 2008.

[34] M. W. Lee and T. S. Collett, "In-situ gas hydrate hydrate saturation estimated from various well logs at the Mount Elbert Gas Hydrate Stratigraphic Test Well, Alaska North Slope," Marine and Petroleum Geology, vol. 28, no. 2, pp. 439-449, 2011.

[35] U. Tinivella, "A method for estimating gas hydrate and free gas concentrations in marine sediments," Bollettino di Geofisica Teorica ed Applicata, vol. 40, no. 1, pp. 19-30, 1999.

[36] U. Tinivella, F. Accaino, and A. Camerlenghi, "Gas hydrate and free gas distribution from inversion of seismic data on the South Shetland margin (Antarctica)," Marine Geophysical Researches, vol. 23, no. 2, pp. 109-123, 2002.

[37] U. Tinivella and J. M. Carcione, "Estimation of gas-hydrate concentration and free-gas saturation from log and seismic data," Leading Edge, vol. 20, no. 2, pp. 200-203, 2001.

[38] U. Tinivella and E. Lodolo, "The Blake Ridge bottom-simulating reflector transect: tomographic velocity field and theoretical model to estimate methane hydrate quantities," Proceedings of the Ocean Drilling Program: Scientific Results, vol. 164, pp. 273281,2000

[39] E. Lodolo, A. Camerlenghi, G. Madrussani, U. Tinivella, and G. Rossi, "Assessment of gas hydrate and free gas distribution on the South Shetland margin (Antarctica) based on multichannel seismic reflection data," Geophysical Journal International, vol. 148, no. 1, pp. 103-119, 2002.

[40] X. Wang, S. Wu, M. Lee, Y. Guo, S. Yang, and J. Liang, “Gas hydrate saturation from acoustic impedance and resistivity logs in the shenhu area, South China Sea," Marine and Petroleum Geology, vol. 28, no. 9, pp. 1625-1633, 2011.

[41] S. N. Domenico, "Elastic properties of unconsolidated porous sand reservoirs," Geophysics, vol. 42, no. 7, pp. 1339-1368, 1977.

[42] F. Gassmann, "Elasitcity of porous media," Viertelijahrsschrift der Naturforschenden Gesselschaft, vol. 96, pp. 1-23, 1951.

[43] N.-Y. Wu, S.-X. Yang, H.-B. Wang et al., "Gas-bearing fluid influx sub-system for gas hydrate geological system in Shenhu Area, Northern South China Sea," Chinese Journal of Geophysics, vol. 52, no. 6, pp. 1641-1650, 2009.

[44] P. Wang, W. L. Prell, and P. Blum, "Ocean drilling program leg 184 scientific prospectus South China Sea, site 1144," in Proceedings of the Ocean Drilling Program, Initial Reports, P. Wang, W. L. Prell, and P. Blum, Eds., vol. 184, pp. 1-97, Ocean Drilling Program, College Station, Tex, USA, 2000.

[45] N. Wu, S. Yang, H. Zhang et al., "Preliminary discussion on gas hydrate reservoir system of Shenhu Area, North Slope of South China Sea," in Proceedings of the 6th International Conference on Gas Hydrates, pp. 6-10, Vancouver, British Columbia, Canada, 2008.

[46] S. L. McDonnell, M. D. Max, N. Z. Cherkis, and M. F. Czarnecki, "Tectono-sedimentary controls on the likelihood of gas hydrate occurrence near Taiwan," Marine and Petroleum Geology, vol. 17, no. 8, pp. 929-936, 2000.

[47] S.-G. Wu, D.-D. Dong, S.-X. Yang et al., "Genetic model of the hydrate system in the fine grain sediments in the northern continental slope of South China Sea," Chinese Journal of Geophysics, vol. 52, no. 7, pp. 1849-1857, 2009 (Chinese).
[48] H. B. Wang, G. X. Zhang, M. Z. Yang et al., "Structural circumstance of gas hydrate deposition in the continent margin, the South China Sea," Marine Geology \& Quaternary Geology, vol. 23, no. 1, pp. 81-86, 2003 (Chinese).

[49] S. X. Yang, H. Q. Zhang, N. Y. Wu et al., "High concentration hydrate in disseminated forms obtained in Shenhu area, North Slope of South China Sea," in Proceedings of the 6th International Conference on Gas Hydrates, pp. 6-10, Vancouver, British Columbia, Canada, 2008.

[50] X. Wang, D. R. Hutchinson, S. Wu, S. Yang, and Y. Guo, "Elevated gas hydrate saturation within silt and silty clay sediments in the Shenhu area, South China Sea," Journal of Geophysical Research B, vol. 116, no. 5, 2011.

[51] P. R. Miles, "Potential distribution of methane hydrate beneath the European continental margins," Geophysical Research Letters, vol. 22, no. 23, pp. 3179-3182, 1995.

[52] Y. H. Rao, "C-program for the calculation of gas hydrate stability zone thickness," Computers and Geosciences, vol. 25, no. 6, pp. 705-707, 1999.

[53] C. Zou and L. Pan, "Comment on "C-program for the calculation of gas hydrate stability zone thickness" by Hanumantha Rao, Computers \& Geosciences vol. 25, pp. 705-707, 1999," Computers and Geosciences, vol. 34, no. 12, pp. 1956-1957, 2008.

[54] J. H. Schön, Physical Properties of Rocks: Fundamentals and Principles of Petrophysics, Handbook of Geophysical Exploration, Seismic Exploration 18, Elsevier, Amsterdam, The Netherlands, 1996.

[55] P. Leclaire, Propagation acoustique dans les milieux poreux soumis augel: modelisation et experience (These de Doctorat en Physique), Universite Paris 7, 1992.

[56] G. T. Kuster and M. N. Toksoz, "Velocity and attenuation of seismic waves in two-phase media-part I: theoretical formulations," Geophysics, vol. 39, no. 5, pp. 587-606, 1974.

[57] G. E. Archer, "The electrical resistivity log as an aid in determining some reservoir characteristics," Transactions of the AIME, vol. 146, no. 1, pp. 54-62, 1942.

[58] O. Serra, Fundamentals of Well-Log Interpretation (vol.1): The Acquisition of Logging Data, Developments in Petroleum Science, Elsevier, Amsterdam, The Netherlands, 1984.

[59] D. W. Hilchie, Applied Openhole Log Interpretation, Douglas W. Hilchie, Golden, Colo, USA, 2nd edition, 1982.

[60] R. W. Zimmerman and M. S. King, "The effect of the extent of freezing on seismic velocities in unconsolidated permafrost," Geophysics, vol. 51, no. 6, pp. 1285-1290, 1986.

[61] X. J. Wang, S. G. Wu, X. Guo et al., "Estimation of gas hydrate saturation in the continental slope, the South China Sea," Marine Geology \& Quaternary Geology, vol. 25, no. 3, pp. 8995, 2005 (Chinese).

[62] R. C. Weast, Handbook of Chemistry and Physics, Chemical Rubber Co. Press, 1992.

[63] E. L. Hamilton, "Shear-wave velocity versus depth in marine sediments: a review," Geophysics, vol. 41, no. 5, pp. 985-996, 1976.

[64] Y. B. Sun, S. G. Wu, D. D. Dong et al., "Gas hydrates associated with gas chimneys in fine-grained sediments of the northern South China Sea," Marine Geology, vol. 311, pp. 32-40, 2012. 

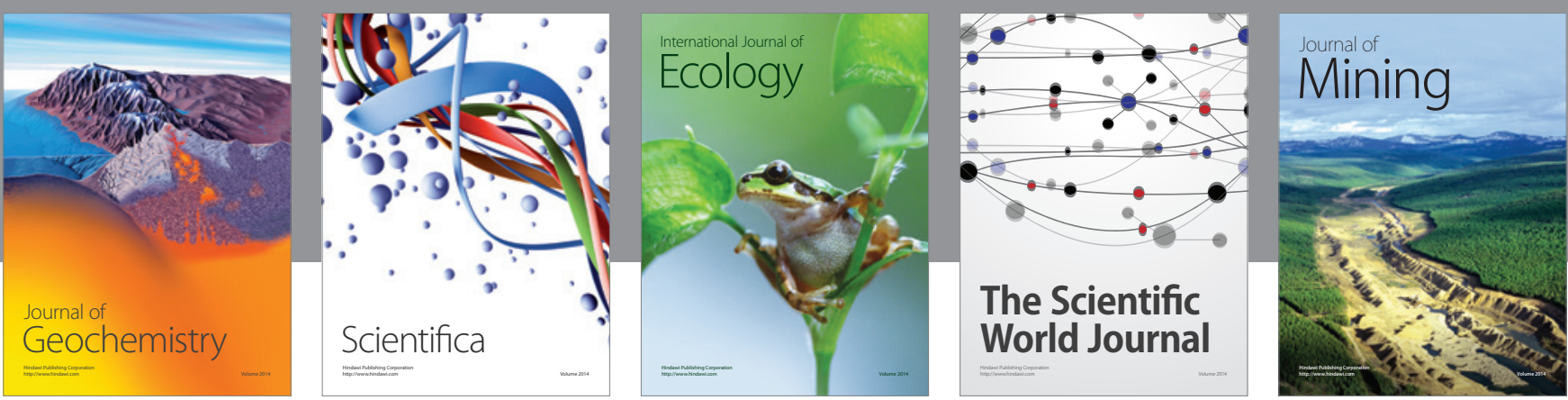

The Scientific World Journal
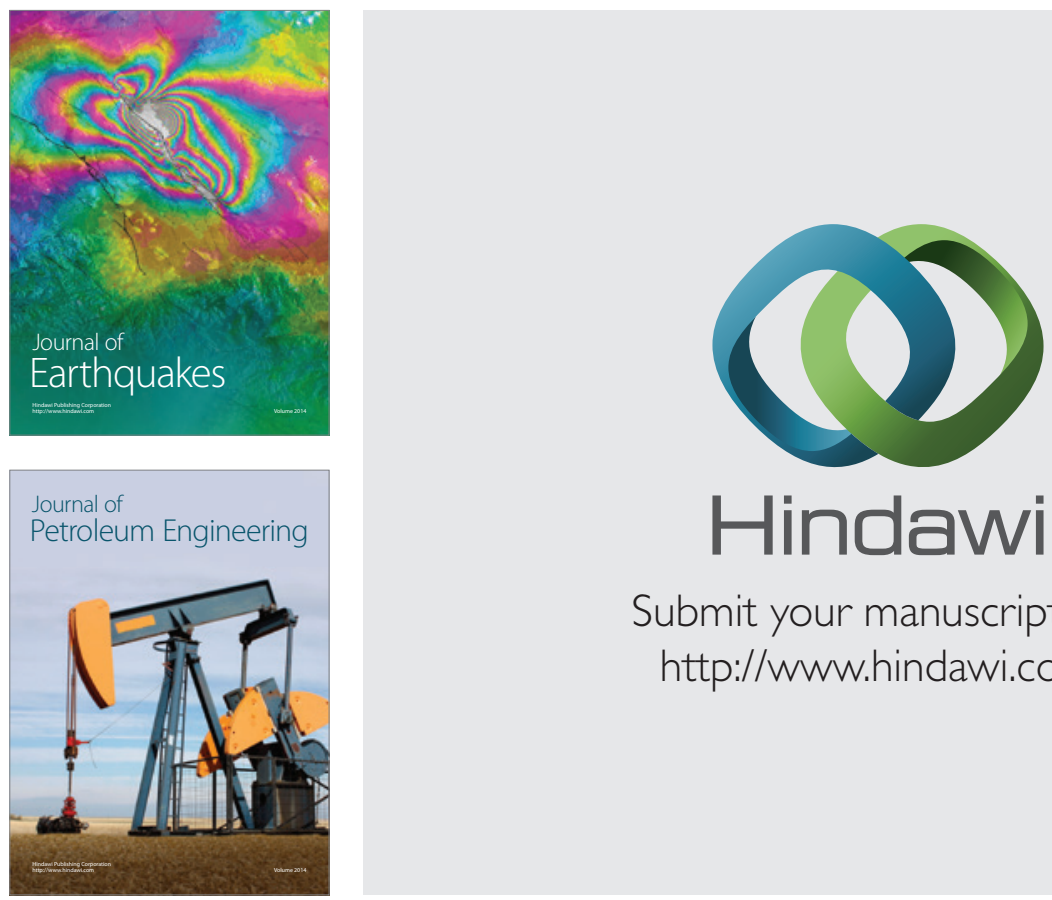

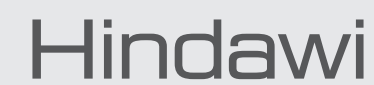

Submit your manuscripts at

http://www.hindawi.com
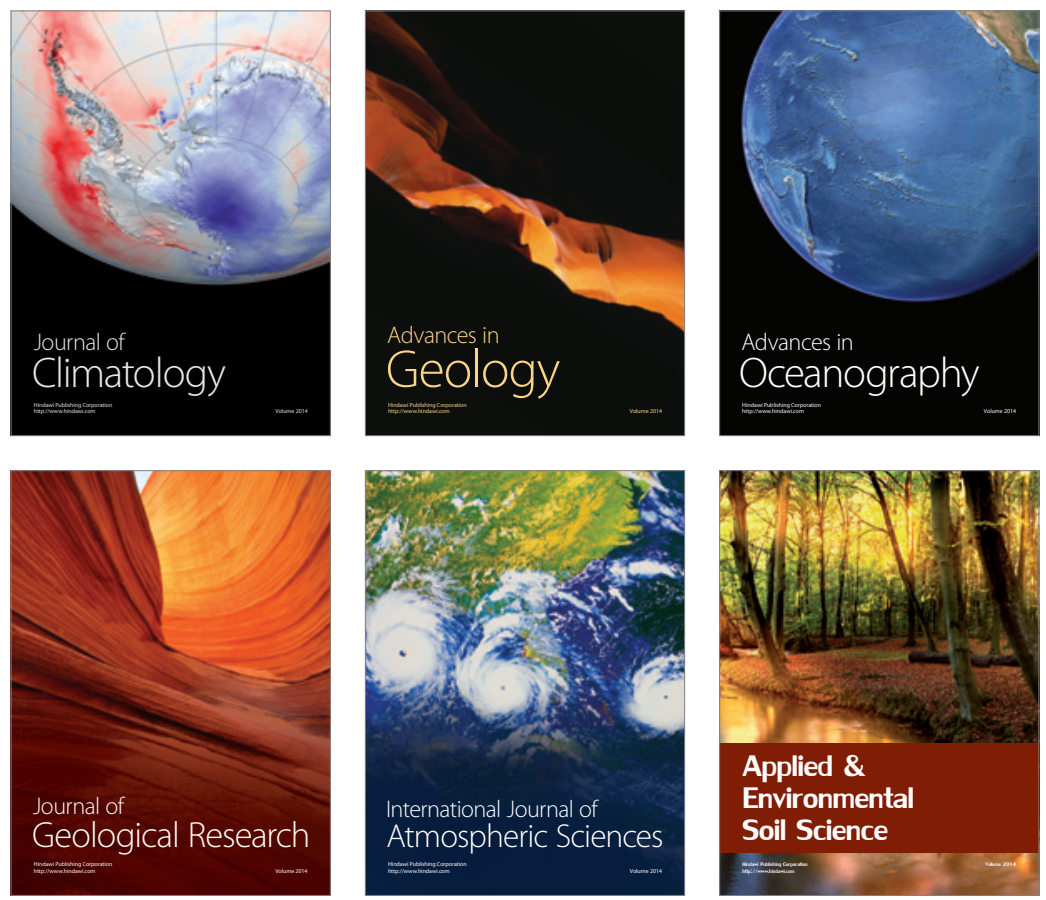
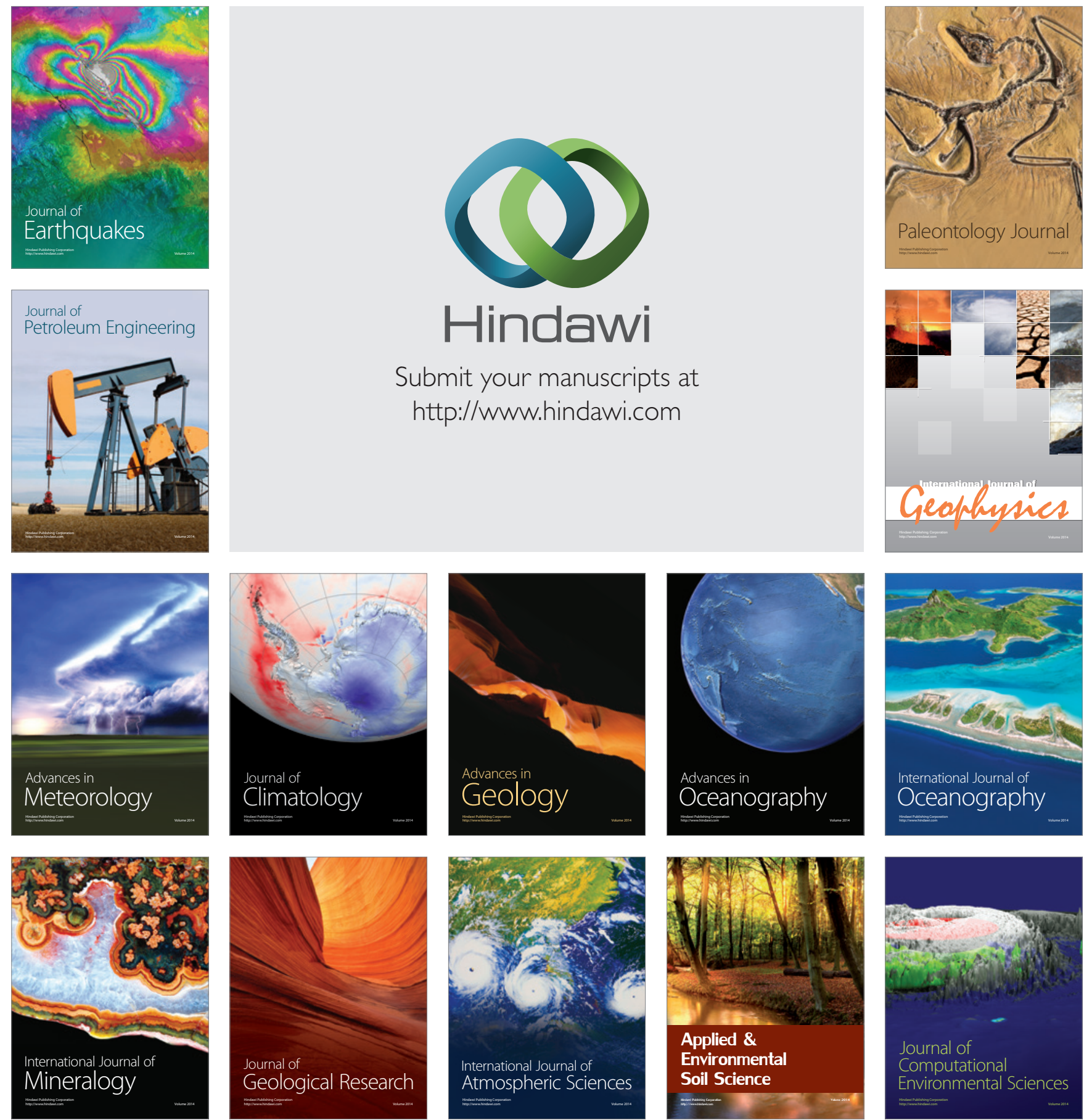